with the rapid progress of exhaustion. No complaint was made of abdominal pain, and on examination nothing abnormal could be detected, with the exception of some slight general tenderness on pressure. The diarrhcea appeared to increase in severity rather than to diminish. The romiting, however, proved intractable, the pulse grew quicker and weaker, the tongue became dry and brown, sordes collected about the teeth and lips, and the patient succumbed in four days to a progressive asthenia. The persistent vomiting and diarrhcea without collapse seemed to indicate an inflammatory affection of the gastro-intestinal tract, but the necropsy proved that death had really resulted from general purulent peritonitis, and that the rupture of a tuberculous ulcer in the vermiform appendix had allowed fæcal matter to escape into the carity of the peritoneum. The clinical records of the remaining cases afford but little help in formulating any rules for the diagnosis of this form of the disease. Abdominal pain may be present throughout the illness, but its onset is never sudden or accompanied by collapse, and indeed the general tenderness over the whole of the abdomen seldom exceeds that which arises from the presence of intestinal ulceration. Occasionally the abdomen may become distended and tympanitic on percussion, but in the majority of our cases these abnormal signs appear to have been absent Vomiting is always the prominent feature, though it varies considerably in its severity in different cases. Unlike the more sthenic variety of the disease, the symptom of constipation is often absent and in not a few instances, as in the one already referred to, diarrhœea proved exceedingly troublesome. The temperature varies in different cases, sometimes showing an inclination to rise above its former point, but more often gradually declining with the approach of death. The pulse exhibits a progressive quickening with enfeeblement of its beat, the first sound of the heart soon becomes toneless or inaudible, the tongue appears dry and brown with sordes about the teeth, and the face often acquires that peculiar drawn and sunken expression so suggestive of acute abdominal disease. The exact duration of life in these cases is difficult to estimate owing to the absence of any positive data concerning the onset of the perforation, but in many instances death seems to have been delayed from five to nine days after the vomiting commenced.

With regard to that variety of symptomless peritonitis which we have alluded to as "latent" the cases at our disposal can only furnish us with three instances in point. In each there had been a long-continued complaint of abdominal pain and diarrhoea, and in two cases the existence of fluid in the peritoneal carity had been diagnosed some days prior to death. The patient appeared suddenly to grow worse without any adequate cause being discovered, but after death it was found that chronic tuberculous disease of the peritoneum was associated with fæcal extravasation arising from perforation of the bowel, which from the appearance it presented was obviously a day or two old. It is now a well-recognised fact that tuberculous disease of the peritoneum renders that sensitive structure proof against many sources of irritation which, under normal conditions, would excite intense inflammation Consequently it mar be taken for granted that when once the serous membrane has fallen a victim to tubercnlous disease even focal extravasation will encounter some difficulty in exciting acnte inflammation of its structure, while from the impaired sensibility of the serous surface the accident will also fail to produce that sudden reflex inhibition of the vital organs which is commonly termed "shock." Although the notes on these cases are extremely scanty it would appear that the sudden supervention of intractable romiting and rapid asthenia in a case of tubercnlons peritonitis with intestinal ulceration, the progress of which had hitherto been somewhat slow. should suggest the possibility of perforation having occurred.

Symptoms of acute peritonitis not unfrequently ensue during the course of chronic phthisis totally independent of perforation of the bowel, and it is therefore important to recognise the various causes from which they may arise. In the first place, local peritonitis around the intestinal ulcers may prove so serere as to closely simulate in its symptoms the more diffuse forms of inflammation; and in one case which we recently had the opportunity of watching but little cloubt was entertained that actual perforation had occurred. The patient, however, lived three weeks and finally succumbed to the pulmonary disease, while the necropsy demonstrated the fact that the abdominal symptoms entirely owed their origin to the existence of two infianed ulcers in the jejunnm. But in such cases as these the onset of the pain is much less sudden than when due to perforation. Collapse, with a sudden fall of temperature, is absent, and the face fails to exhibit the peculiar expression indicative of fatal mischief in the abdomen. It should also be remembered that actual perforation is of extremely rare occurrence and the subsequent peritonitis invariably terminates fatally within three days.

Secondly, during the same period of time in which our cases of genuine perforation occurred we find the records of nineteen other cases where death had resulted from purulent peritonitis, for which neither perforation of the bowel, tuberculous disease of the serous membrane, nor renal mischief could satisfactorily account. In each instance the bases of the intestinal ulcers were much inflamed, and althongh it is possible that in a few cases a small perforation may have given rise to the condition without its presence being detected at the necropsy. But the clinical histories of these cases make no mention of a sudden onset of pain attended by collapse, and the absence of this important diagnostic sign is almost conclusive evidence against perfora. tion having occurred in any case. It is probable, therefore. that the condition of general peritonitis was the result of extension by contiguity. Lastly, it is possiblo that acute tuberculous peritonitis might at an early stage be confounded with an inflammatory affection of the peritoneum arising from the intestinal lesion. In this disease, however, initial collapse is entirely absent, the abdominal pain is more gradual in its onset and less severe, and fever is the rule, not the exception. Here, again, the comparative frequency of the two diseases should be borne in mind, for we find that while tuberculous peritonitis existed in nearly 4 per cent. of all the cases of phthisis which came to a necropsy, acute peritonitis resulting from perforation only occurred 15 times in 2000 .

(To be concluded.)

\section{A PRELIMINARY NOTE ON FLEXION AND VERSION OF THE UTERUS.}

BY JAMES OLIVER, M.D., F.R.S. EdIN., M.R.C.P. LOND.

OUR text-books on diseases of women, it is true, devote a large amount of space to the consideration of the various flexions and versions of the uterus ; that, however, they impart any true knowledge regarding the manner in which these altera. tions are produced is extremely doubtful. The mere fact that these variations have been recognised for many generations is no criterion. They are apparent and obvious changes, and no high degree of intelligence or great amount of training is requisite for their detection; and had they failed from the earliest period in the history of medicine to attract attention, we should indeed have been justified in expressing the most profound astonishment. The majority of practitioners and gynæcologists even of the present day are, I regret to say, contented to know that they possess that aptitude which enables them to detect alterations in the configuration or position of the uterusalterations which they cannot, in fact, help detecting. A man endowed with ordinary sight, in looking towards the heavens on a clear night, recognises the stars which stud the azure vault, but without some special training he is unible to determine the distances and magnitudes and courses of the planetary orbs as they roll along the ethereal plains, and these facts are only reached and disclosed by means of an intellectual effort. The various pessaries which from time to time have been devised for the purpose, if possible, of restoring the nterus to and maintaining it in its recognised form and position are carefully enumerated and each is usually described with much exactness. The good effects produced by the application and adaptation of these mechanical agents are duly paraded, but the panegyrist leaves the imagination to picture to itself the manner in which these so-called supports can affect the configuration or position of the uterus and restore this organ to its natural shape and location. "An unreasoned philosophy, even though true, carries no guarantee of its truth. It may be true, but it cannot be certain, because all certainty depends on rigorous eridence, on strict demonstrative proof. Therefore no certainty can attach to the conclusions of an unreasoned philosophy."

Before directing our attention to the consideration of tho: $\theta$ 
changes which produce an alteration in the configuration or position of the nterus let me discuss, first of all, the following propositions, which, says Thomas, ${ }^{1}$ "present the views upon the subject of versions and flexions which will be found to bear the test of experience." 1 . "Versions and flexions of the womb may, but very rarely do, exist without causing any :ymptoms, for in themselves they do not constitute disease." The logic of this precept is strange. On authority, but not by reason, we are asked to believe that versions and flexions tho not constitute disease and that consequently, although they may not produce symptoms, they are nevertheless much more likely to give rise to discomfort and prove troublesome. Are we to infer that the structural changes which result in the production of these displacements do not constitute disease? If not, they must then be normal variations. No process of reasoning will, I fear, lead us to this conclusion. They are most assuredly the result of some derangement, physical or chemical. Judging alone from the manner in which we are recommended to treat these displacements we are compelled tu admit that the alteration, whether in configuration or in position, is in reality the disease. By the application of what "they" term a well-adjusted pessary the uterus will be restored to its natural shape and situation. Now every. whe will admit that a system which is reasoned is of some value even although it may not be true, whereas haphuzard statements are absolutely worthless, and, worse than this, they are misleading. 2. "By interfering with the escape of menstrual blood, by disordering uterine circulation and keeping up hyperæmia, by causing pressure and friction from contact with surrounding parts, and by creating a barrier to the entrance of seminal fluid, they become is a rule of great importance and require special attention." We have no evidence that flexions or versions interfere with the escape of the menstrual blood. Many women suffer more or less during menstruation, and although we may occasionally in such detect some alteration in the configuration or position of the aterus, it does not necessarily follow that the pain is due to an interference with the escape of blood. Firequently we find women with decided flexions and versions who suffer no discomfort whatever during menstruation. We are too apt to jump at conclusions regarding cause and effect, and for this reason statistics are apt to prove fallacious. We have no evidence either that these variations disorder the circulation. Those who assume that the circulation is disturbed forget apparently that they are dealing with organic tructures, with tissues which are endowed with a large amount of power of adaptation to circumstances. In the female dugong we have a uterus which presents a peculiar corkscrew shape, but it is perfectly evident that the irculation of the organ is not thereby disordered. If llexion is due to want of tone in the uterus, then the ressels will not receive that amount of support from the tissues and the blood will consequently pass more sluggishly. In this case, however, the circulation is disturbed not by the flexion, but by the cause of the flexion; the disturbance is nevertheless augmented by the contiruration or position of the uterus. In the animal and regetable kingdoms we have abundant proof that mere shape dues not interfere with the passage of that fluid which nourishes the tissues. The tendrils and branches of plants perform many gyrations and assume a variety of shapes withwut the vascular system in any part of its course being necessarily disturbed. Again, the influence of pressure and friction is undoubtedly exaggerated, for everyday we find new urowths developing in the pelvis, arising, it may be, from the utwrus or ovaries and attaining a great size. and yet the pres- ure exercised by these produces little or no discomfort unless they become confined, when the increased tension necessarily yroduces pressure symptoms. It is alleged, too, that texions and versions are a cause of sterility, as they 'reate a barrier to the entrance of the seminal fluid. If we examine the genital organs of the females of luany of the lower animals we shall observe that greater iarriers to the entrance of seminal fiuid exist naturally in lwany of them. The spermatozoa appear to experience no Hifliculty whatever in effecting an entrance into the corkscrewhaped uterus of the dugong In the cervix and body of the uterus of the sheep and goat we find groups of laminæ presenting the appearance of a number of successive ora tincæ, and many no doubt would be disposed to affirm that these irregularities in the canal would hinder the progression of the :permatozoa. A careful study of the various methods whereby

1 Practical Treatise of Diseases of Women, edition 1880, p. 365. the process of fecundation is carried on in plants and animals and a close examination of the genital tract in mammalia compel us to admit that the spermatozon and ova are attracted towards each other and that they do not meet and coalesce simply because they happen to be traversing the same passage. It sometimes happens that this elective affinity is absent and fecundation is then impossible. In the case of fishes, for example, it is this elective affinity - this attraction between the ova and spermatozoa - which kecps the species pure; without this influence hybrids would abound. In the case of the ornithorhynchus we find a cervix uteri located on each side of the roof of the uro-genital canal. Each cervix presents two orifices, one-the lower--communicates with the ureter, whilst the other-the upper-leads to the body of the uterus. If, therefore, the process of fertilisation depended simply upon chance we would be justified in asserting because of the structural arrangememt that the female ornithorhynchus would seldom become pregnant, for the spermatozoa would tend to enter the first opening which leads to the ureter, and would thus fail in their mission. It is evident, however, that the spermatozoa seldom, if ever, enter this opening, but are attracted towards that opening which leads to the uterus and ovary. In the macropus majora marsupial animal-we find also a structural arrangement of such a character that if the meeting of the spermatozoa and ova depended purely upon chance the species would run a fair prospect of being speedily extinguished. 3. "Often being the results, as they are sometimes the causes, of uterine and peri-uterine diseases, their treatment should be combined with efforts at the alleviation of these states." 'There can be no doubt that the displacements of the uterus are the result of intrinsic or extrinsic changes, but I am fully convinced that if greater caution were exercised in treating these malpositions and altered configurations of the uterus many women would be freed from a great deal of suffering, and many who have become invalided in consequence of a too vigorous treatment would pass through life more comfortably.

Gordon.square, W.C.

\section{THE}

\section{RADICAL CURE OF URETHRAL STRICTURE. 1}

BY W. BRUCE CLARKE, F.R.C.S. ENG.,

SURGEON TO THE WEST LONDON HOSPITAL ; ASSISTANT SURGEON TO ST. BARTHOLOMEW'S HOSPITAL; EXAMINER IN SURGERY TO THE UNIVERSITY OF OXFORD.

THOUGH it is universally recognised that strictures of the urethra differ in their situation, cause and arrangement, no attempt has, so far as I am aware, been made to lay down any principles which should guide the surgeon in dealing with these separate varieties. Excluding the traumatic form which, as is so well known, differs from the organic stricture in its extreme intractability, we seem hardly to have advanced much further in our ideas of the causation and pathology of the disease than had John Hunter. He recognised three varieties-true spasmodic, persmanent and mixed, and states further and with equal truth that spasm plays an important part in most strictures. Subsequent writers on the question have little to add to this view and the less we stray from these simple statements the greater chance of our getting a clear conception of what urethral stricture is and how to treat it. One point alone we may add to this description to make it complete: we must recognise that congestion plays a very considerable part in many a stricture that comes before us. There is another factor of equal if not of greater importance which remains to be determined before a stricture can be successfully treated. Its exact locality must be determined, and this is doubly necessary, because, for reasons that are not altogether explainable, the locality affected influences both the course which the disease follows and the means which are to be taken for its relief. It is often assumed that the appearances of diseased structures which are so familiar to the student of museums form an all-sufficient basis to enable us to carry out a successful line of treatment. Nothing, I am persuaded, is more untrue and nothing more likely to bring surgery into unmerited disrepute than the accepta tion of such a dictum, as some writers have accepted lit without any reservation whatsoever. So far as it goes !it

I A paper read before the West London Melico-Chirurgical Society, Jan. 8th, 1892 . 